\title{
ATIVIDADE BIOLÓGICA DAS TOXINAS DO BT, CRY 1A(b) E CRY 1F EM Spodoptera frugiperda (SMITH) (LEPIDOPTERA: NOCTUIDAE)
}

\author{
JOSÉ M. WAQUIL ${ }^{1}$, FRANCYS M. F. VILELLA², BLAIR D. SIEGFRIED ${ }^{3}$, JOHN E. FOSTER ${ }^{3}$
}

\author{
${ }^{1}$ Bolsista CNPq / Pesquisador, Embrapa Milho e Sorgo. Caixa Postal 151, CEP. 35701-970 Sete Lagoas, MG. E-mail: \\ waquil@cnpms.embrapa.br (autor para correspondência) \\ ${ }^{2}$ Departamento de Zoologia - UnB. Campus Universitário, CEP. 70910-900 Brasília, DF. \\ ${ }^{3}$ Department of Entomology/UN-L, 202 Plant Industry Bldg., Lincoln, NE 68583-0816.
}

Revista Brasileira de Milho e Sorgo, v.3, n.2, p.161-171, 2004

\begin{abstract}
RESUMO - Atualmente, há duas diferentes toxinas do Bacillus thuringiensis (Bt) disponíveis em milho transgênico. Entretanto, há poucas informações sobre a toxicidade dessas proteínas puras Cry 1A(b) e Cry 1F para a lagarta-do-cartucho do milho (LCM), Spodoptera frugiperda (Smith), usando o método de tratamento superficial da dieta. Os bioensaios foram conduzidos, usando um gradiente de concentração para as duas toxinas. Cada tratamento foi infestado artificialmente com larvas da LCM recém-eclodidas e mantidas sob temperatura constante e no escuro. Dez dias após a infestação, o número de larvas sobreviventes e a inibição de crescimento baseado na biomassa foram avaliados. Os dados de mortalidade foram submetidos à análise de "Probit". As $\mathrm{CL}_{50}$ estimadas para Cry1A(b) e Cry1F foram, respectivamente, $689,81 \mathrm{ng} / \mathrm{cm}^{2}$ e $36,46 \mathrm{ng} / \mathrm{cm}^{2}$. A CL 50 foi suficiente para inibir o acúmulo de biomassa das larvas em 91,61\% e 89,81\% para Cry $1 \mathrm{Ab}$ e Cry1F, respectivamente. As larvas que sobreviveram por dez dias nas dietas tratadas com o Cry $1 \mathrm{~A}(\mathrm{~b})$ foram transferidas para dieta não tratada e observadas até a emergência dos adultos. Das larvas sobreviventes, $62,8 \%$ recuperaram seu desenvolvimento, acumulando a biomassa de uma pupa normal. Portanto, a atividade biológica da toxina do $B t$ vai além da simples toxicidade, incluindo uma significativa inibição de alimentação. Esse fato tem implicações importantes para o desenvolvimento de estratégias para o manejo da resistência.
\end{abstract}

Palavras-chave: Insecta, biologia, manejo de pragas, toxicologia, resistência de plantas, Bacillus thuringiensis.

\section{BIOLOGICAL ACTIVITY OF BT TOXINS, CRY 1A(b) AND CRY 1F ON Spodoptera frugiperda (SMITH) (LEPIDOPTERA: NOCTUIDAE)}

\begin{abstract}
There are currently two different toxins from Bacillus thuringiensis (Bt) available in transgenic maize. However, there is limited information regarding the toxicity of purified Cry $1 \mathrm{Ab}$ and Cry1F toxins to fall armyworm (FAW), Spodoptera frugiperda (Smith), using a surface exposure method with artificial diet. Bioassays were conducted using a range of concentrations for both toxins. Each treatment was artificially infested with neonate FAW larvae and maintained under constant temperature and complete darkness. Ten days after exposure, the number of surviving larvae and growth inhibition based on biomass were evaluated. The mortality data were subject to Probit analysis. The estimated $\mathrm{LC}_{50}$ 's for Cry $1 \mathrm{Ab}$ and Cry $1 \mathrm{~F}$ were, respective $689.81 \mathrm{ng} / \mathrm{cm}^{2}$ and 36.46 $\mathrm{ng} / \mathrm{cm}^{2}$. The $\mathrm{LC}_{50}$ was enough to inhibit the biomass accumulation of larvae by $91.61 \%$
\end{abstract}


and $89.81 \%$ for Cry $1 \mathrm{Ab}$ and Cry $1 \mathrm{~F}$, respectively. The larvae that survived after 10 days on $\mathrm{Cry} 1 \mathrm{Ab}$ treated diet were transferred to untreated diet and observed until adult emergence. Out of the surviving larvae, $62.8 \%$ recovered their development reaching the normal pupa biomass. Therefore, the biological activity of $B t$ toxin extends beyond toxicity including a significant feeding inhibition. This fact has significant implications for the development of resistance management strategies.

Key words: Insecta, biology, pest management, toxicology, insect plant resistance, Bacillus thuringiensis

A lagarta-do-cartucho do milho (LCM) Spodoptera frugiperda (Smith) pode causar perdas de 17 a 38,7\% na produção do milho, dependendo do estádio de desenvolvimento das plantas atacadas (Carvalho, 1970) e da cultivar (Williams et al., 1990). Entretanto, esse percentual independe do estado nutricional da planta, isto é, do potencial de produção (Cruz et al., 1999). Essa espécie tem causado sérios prejuízos, também, na cultura do sorgo, cujas perdas podem chegar a mais de $20 \%$ (Cortez \& Waquil, 1997) e no algodão (Gallo et al 2002). Para o manejo dessa praga, são recomendadas várias estratégias, incluindo métodos culturais, químicos e biológicos (Cruz \& Waquil, 2001). Hoje, com a disponibilidade de plantas transgênicas expressando diferentes toxinas do $B t$, essa estratégia de manejo da LCM precisa ser cuidadosamente estudada. Os aspectos legais e regulatórios para o uso das plantas transgênicas no Brasil foram discutidos por Fontes (2003).

Como bioinseticida, a bactéria Bacillus thuringiensis (Berliner) (Bt), estirpe HD1, vem sendo usada há décadas (Feitelson et al., 1992) e está registrado sem limitação de uso, para o controle de várias espécies-praga de Lepidoptera. Foi constatado que, no campo, existem várias espécies e dentro destas, populações de $B t$. Hoje, centenas de isolados das mais diferentes regiões estão registrados na literatura. Uma das frações ativas produzidas pelo $B t$ são proteínas acumuladas em forma de cristal no interior das células, denominadas "Cry", que podem constituir mais de $30 \%$ do total de proteínas da célula (Hermstadt et al., 1986). As seqüências gênicas conhecidas, responsáveis pela expressão dessas proteínas (toxinas), podem ser encontradas na Internet, no endereço: http://www.biols.susx.ac.uk/home/ Neil_Crickmore/Bt.

Em bioensaios, tem sido demonstrada a especificidade das toxinas puras para as diferentes espécies de insetos (MacIntosh et al., 1990). Especificamente para as principais espécies de lepidópteros-praga do milho, foram registradas as seguintes toxinas com maior atividade: Cry 1D e Cry 1F para o controle de $S$. frugiperda, Cry 1A(c) para Helicoverpa zea, Cry 1B para Diatraea saccharalis e D. grandiosella (Bohorova et al., 1997) e Cry 1C para S. exigua (Visser et al., 1990). Em Ostrinia nubilalis, a atividade dessas toxinas pode variar de 2 a 7 vezes em função da origem geográfica da população submetida à análise (Marçon et al., 1999).

Embora, a campo, os bioinseticidas à base do isolado HD1 do $B t$ não tenham apresentado bons resultados no controle da LCM (Waquil et al., 1982), o milho transgênico, expressando a toxina Cry $1 \mathrm{~A}(\mathrm{~b})$, tem apresentado níveis razoáveis de resistência (Williams et al., 1998a). Adicionando-se palha de milho transgênico, liofilizada, em dieta artificial, notou-se redução de $40 \%$ na sobrevivência e de $94 \%$ na biomassa das larvas $S$. frugiperda (Williams et al., 1998a). Nas dietas contendo apenas estilo-estígma de 
milho transgênico, não se observou mortalidade, mas notou-se redução significativa no desenvolvimento dos insetos (Williams et al., 1998b). Para a LCM, a resistência de plantas de milho, expressando toxinas do $B t$, variou desde altamente efetiva (Cry 1F), intermediárias (Cry 1A(b) e Cry 1A(c)) e sem atividade alguma (Cry 9C) (Waquil et al., 2002). No controle da lagarta-elasmo, Elasmopalpus lignosellus, todas as toxinas Cry [1F, 1A(b), 1A(c) e 9C] foram eficientes (Vilella et al., 2002).

Para as populações brasileiras da LCM, existem poucos estudos. Entre 58 cepas testadas, a mais eficiente foi o Bt morrisoni, causando cerca de $80 \%$ de mortalidade, sendo que as demais cepas apresentaram menos de $40 \%$ de eficiência (Polanczyk et al., 2003). Por outro lado, a avaliação de plantas transgênicas com o gene $B t$ no Brasil é também rara. Avaliando milho $B t$, expressando a toxina Cry $1 \mathrm{~A}(\mathrm{~b})$ em condições de campo durante dois anos e em diferentes locais, foi observado um controle eficiente da LCM (Fernandes et al., 2003).

O objetivo deste trabalho foi avaliar a atividade biológica das toxinas Cry $1 \mathrm{~A}(\mathrm{~b})$ e Cry $1 \mathrm{~F}$ sobre a LCM, utilizando o método de tratamento da superfície da dieta artificial. Esse método tem a vantagem de demandar pequenas quantidades das toxinas e produzir resultados consistentes. Além disso, esse método pode ser utilizado tanto na prospecção de novos produtos como no monitoramento de populações de campo para o manejo da resistência de espécies-alvo.

\section{Material e Métodos}

Nos laboratórios do Departamento de Entomologia da Universidade de Nebraska em Lincoln (UNL), NE, foram mantidas colônias de Spodoptera frugiperda e conduzidos bioensaios, visando avaliar a susceptibilidade dessa espécie às toxinas do Bacillus thuringiensis $(B t)$, Cry $1 \mathrm{~A}(\mathrm{~b})$ e Cry $1 \mathrm{~F}$ e a atividade biológica dessas toxinas sobre a mortalidade, inibição de crescimento e recuperação de larvas sobreviventes.

Toxinas do $\boldsymbol{B} \boldsymbol{t}$ - A toxina Cry1A(b) ativada foi fornecida pela companhia Monsanto (St. Louis, MO, EUA), purificada da protoxina Cry1A(b) solúvel, a qual foi tratada com tripsina bovina pancreática até que cerca de $90 \%$ da proteína foi convertida à toxina. A toxina Cry1F foi obtida da Dow Agroscience (Indianápolis, IN, EUA) e produzida através da fermentação de Pseudomonas fluorescens recombinante, cepa MR872. Após fermentação e lise das células de $P$. fluorescens, os cristais foram separados e purificados. A forma ativada de Cry1F foi obtida por meio de digestão por tripsina e, posteriormente, purificada por meio de cromatografia de troca iônica.

Colônia de insetos - Colônias da lagarta-do-cartucho do milho (LCM) foram mantidas em laboratório, utilizando dieta artificial fornecida pela divisão de Entomologia da BIO-SERV ${ }_{\mathrm{TM}}{ }^{\circledR}$ (www.bio-serv.com) mantida em copos plásticos transparentes com tampa. Os adultos foram mantidos em gaiolas, confeccionadas a partir de potes plásticos de aproximadamente $1 \mathrm{~L}$. A superfície interna do pote foi revestida por folha de papel toalha de onde as posturas dos adultos foram recolhidas. A alimentação dos adultos foi feita por meio de um pavio de algodão, mantendo uma das extremidades imersa numa solução de sacarose $10 \%$. Os insetos adultos foram trocados de gaiola a cada dois dias, quando se colhiam as posturas. As posturas foram armazenadas em sacos plásticos, os quais foram mantidos em BOD com temperatura controlada, até o inicio da eclosão de larvas e foram, então, utilizadas para a manutenção da colônia ou para a realização de bioensaios.

Mortalidade larval - Foram conduzidos, simultaneamente, dois bioensaios, usando o método 
de tratamento da superfície da dieta artificial, em bandejas multicelulares com 8 blocos de 16 células/bandeja (Marçon et al., 1999). Foi utilizado $1 \mathrm{~mL} /$ célula de dieta artificial e, na superfície desta, foram aplicados 30 $\mathrm{\mu l} /$ célula de cada concentração das toxinas, diluídas em Triton $100^{\circledR}$ $0,1 \%$. Foram utilizadas sete diluições (1:2), variando de 15,625 a $1000,000 \eta \mathrm{g} / \mathrm{cm}^{2}$ para a toxina Cry $1 \mathrm{~A}(\mathrm{~b})$ e de 7,810 a $500,000 \eta \mathrm{g} / \mathrm{cm}^{2}$ para a Cry 1F. Depois de deixar a superfície secar por aproximadamente $1 / 2$ hora, uma larva da LCM recém-eclodida foi transferida para cada célula, cobrindo-se, em seguida, cada bloco de 16 células com um plástico adesivo transparente. Essa é uma cobertura especial para a bandeja, que evita a fuga das larvas, mas permite a troca gasosa através de pequenos poros. As bandejas, depois de preparadas e etiquetadas, foram incubadas em câmaras escuras, sob temperatura constante de $27^{\circ} \mathrm{C}$. Dez dias após a infestação, os bioensaios foram avaliados, contando-se o número de insetos sobreviventes. Os dados obtidos foram submetidos à análise de "Probit", utilizando-se o programa SAS.

Inibição do crescimento larval - Após a contagem dos insetos vivos e mortos na atividade anterior, estimou-se a biomassa para cada inseto sobrevivente, por meio de uma balança de precisão. Os dados obtidos foram submetidos à análise de regressão, utilizando as concentrações das toxinas como variável independente $\mathbf{x}$ e a taxa de inibição de crescimento como variável dependente y. Assim, foi estimada uma equação para a inibição de crescimento larval em função da dose da toxina, com base na biomassa dos insetos sobreviventes.

Recuperação do desenvolvimento larval - Após a avaliação da mortalidade e do crescimento larval dos insetos submetidos às toxinas do $B t$, por 10 dias, as larvas sobreviventes foram transferidas para copos plásticos com tampa, contendo dieta artificial sem toxina. Os copos contendo as larvas sobreviventes, foram acondicionados em bandejas que foram novamente incubadas em BOD sob as mesmas condições do bioensaio. Cinco dias após essa repicagem, ou seja, aos 15 dias de idade, as larvas foram novamente pesadas, anotando-se a biomassa. No primeiro dia de observação da pupa, esta foi pesada para se anotar a biomassa de cada indivíduo. Como o número de observações (larvas sobreviventes) variou dentro do gradiente de dose estudado, os resultados foram analisados com base no intervalo de confiança da média e na correlação entre a biomassa das larvas, após exposição à toxina, e a biomassa da respectiva pupa.

\section{Resultados e Discussão}

Mortalidade larval - Os dados da taxa de mortalidade para cada toxina, submetidos à análise de "Probit", permitiram estimar os parâmetros que geraram as seguintes equações:

$\mathrm{Y}_{1 \mathrm{~F}}=1,86+2,02 \mathrm{X}_{1 \mathrm{~F}}$ (para toxina Cry $1 \mathrm{~F}$ ) e

$\mathrm{Y}_{1 \mathrm{~A}(\mathrm{~b})}=2,66+0,83 \mathrm{X}_{1 \mathrm{~A}(\mathrm{~b})}$ [para toxina Cry $\left.1 \mathrm{~A}(\mathrm{~b})\right]$, onde,

$X=$ logaritmo da dose da toxina $\left(\eta \mathrm{g} / \mathrm{cm}^{2}\right)$ e

$\mathrm{Y}=\mathrm{o}$ valor de "Probit" a ser convertido em porcentagem de mortalidade.

$\mathrm{Na}$ Tabela 1, estão apresentadas as probabilidades de mortalidade da LCM com base nas curvas estimadas para as toxinas do $B t$ estudadas. $\mathrm{A} \mathrm{CL}_{50}$ das toxinas Cry $1 \mathrm{~A}(\mathrm{~b})$ e Cry1F encontradas para $S$. frugiperda foram de 689,81 e $36,46 \mathrm{\eta g} / \mathrm{cm}^{2}$ de dieta, respectivamente. Para a toxina Cry $1 \mathrm{~F}$, a aproximação da estimativa está boa, tendo em vista a escolha das concentrações que permitiram um bom ajuste da reta pela obtenção de respostas, variando de 0 a $100 \%$ de mortalidade. As estimativas obtidas para a toxina Cry 1 A(b) estão satisfatórias, abaixo dos 58\% 
TABELA 1. Concentração letal e intervalo de confiança para cada probalidade de mortalidade causada pelas toxinas do $B t$ sobre a lagarta-do-cartucho do milho, Lincoln, NE, 2000.

\begin{tabular}{|c|c|c|c|c|c|c|}
\hline \multirow{3}{*}{$\begin{array}{l}\text { Probabili- } \\
\text { dade (\%) }\end{array}$} & \multicolumn{3}{|c|}{ Cry 1 A(b) } & \multicolumn{3}{|c|}{ Cry 1F } \\
\hline & \multirow{2}{*}{$\begin{array}{c}\text { Concentração } \\
\left(\eta \mathrm{g} / \mathrm{cm}^{2}\right)\end{array}$} & \multicolumn{2}{|c|}{ Intervalo confiança $(95 \%)$} & \multirow{2}{*}{$\begin{array}{c}\text { Concentração } \\
\left(\eta g / \mathrm{cm}^{2}\right)\end{array}$} & \multicolumn{2}{|c|}{ Intervalo confiança (95\%) } \\
\hline & & Inferior & Superior & & Inferior & Superior \\
\hline 01 & 001,05 & 000,20 & 002,97 & 002,48 & 001.47 & 003.69 \\
\hline 05 & 007,03 & 002,37 & 013,98 & 005,45 & 003.66 & 007.40 \\
\hline 10 & 019,37 & 008,81 & 032,39 & 008,30 & 005.94 & 010.75 \\
\hline 50 & 689,81 & 459,55 & $1.241,00$ & 036,46 & 031.09 & 042.33 \\
\hline 90 & $24.561,00$ & $8.823,00$ & $129.291,00$ & 160,21 & 129.54 & 209.24 \\
\hline 95 & $67.622,00$ & $20.041,00$ & $491.001,00$ & 243,75 & 188.94 & 338.21 \\
\hline 99 & $452.007,00$ & $92.947,00$ & $6.027 .744,00$ & 535,58 & 380.15 & 839.82 \\
\hline
\end{tabular}

de mortalidade, mas, para valores superiores a este, as estimativas podem apresentar uma margem substancial de erro, tendo em vista que o máximo de mortalidade obtida foi $58 \%$. Esse fato fica mais evidente quando se compara o limite inferior e superior, do intervalo de confiança da média, entre si ou entre as toxinas. No caso da toxina Cry $1 \mathrm{~A}(\mathrm{~b})$, os limites variam de 459,55 a $1.241,00 \mathrm{\eta g} / \mathrm{cm}^{2}$, sendo que a $\mathrm{CL}_{50}$ é de 689,81 , ou seja, o intervalo para o limite superior é quase 2 vezes maior que o inferior. Para a toxina Cry $1 \mathrm{~F}$, o intervalo entre os limites é consideravelmente menor e a $\mathrm{CL}_{50}$, de $36,46 \eta \mathrm{g} / \mathrm{cm}^{2}$, ficou praticamente eqüidistante entre os limites. Como a curva de mortalidade da LCM pela toxina Cry 1A(b) não está satisfatoriamente estimada para o limite superior de mortalidade, a comparação entre as duas toxinas foi feita somente com base na $\mathrm{CL}_{50}$. Comparando-se as $\mathrm{CL}_{50}$ das duas toxinas, observou-se que para Cry $1 \mathrm{~F}$ foi cerca de 19 vezes menor, mostrando a maior atividade dessa toxina contra a LCM. Esses dados confirmam o registro de que, para a LCM, a toxina Cry $1 \mathrm{~F}$ é mais ativa que a Cry $1 \mathrm{~A}(\mathrm{~b})$ (Bohorova et al., 1997). Avaliando a susceptibilidade de Ostrinia nubilalis à toxina Cry $1 \mathrm{~A}(\mathrm{~b})$, em populações obtidas em 10 Estados dos EUA e do Norte da Itália, foi verificado que a $\mathrm{CL}_{50}$ variou de 2,22 a $7,89 \mathrm{\eta g} / \mathrm{cm}^{2}$ (Marçon et al., 1999). Isso indica que a atividade dessa toxina sobre $O$. nubilalis é cerca de 90 vezes maior que sobre a LCM. Mesmo a toxina Cry $1 \mathrm{~F}$, a mais ativa sobre a LCM, ainda é quase 5 vezes menos ativa sobre $O$. nubilalis que a Cry $1 \mathrm{~A}(\mathrm{~b})$.

Inibição do crescimento larval - Como na análise de "Probit", utilizou-se a transformação logarítmica decimal para as doses das toxinas (Marçon et al, 1999). Para a taxa de inibição de crescimento, foram testadas várias transformações e a que melhor se ajustou, para o intervalo de dados obtidos, baseando-se no $\mathrm{R}^{2}$, foi arcsen raiz da proporção de inibição (biomassa dos insetos tratados/biomassa dos insetos controle). Como o bioensaio foi planejado para se estimar as concentrações letais, os dados obtidos para inibição de crescimento variaram de 66,5 a $100 \%$ de inibição para a toxina Cry $1 \mathrm{~F}$ e de 32,0 a $96,0 \%$ para a toxina Cry 1A(b). Novamente, como as estimativas basearam-se num intervalo relativamente estreito de dados, as extrapolações baseadas nas curvas podem incorrer em erros significativos. Entretanto, dentro do intervalo de dados 
obtidos, foi possível estimar as equações apresentadas nas Figuras 1 e 2, respectivamente para as toxinas Cry $1 \mathrm{~A}(\mathrm{~b})$ e Cry $1 \mathrm{~F}$.

Aplicando-se os valores da $\mathrm{CL}_{50}$ da população nas respectivas equações (Figuras 1 e 2) para cada uma das toxinas, obteve-se uma estimativa da inibição de crescimento de $91,61 \%$ para a Cry $1 \mathrm{~A}(\mathrm{~b})$ e $89,81 \%$ para a Cry $1 \mathrm{~F}$. Verificouse que as taxas de inibição de desenvolvimento das larvas foram semelhantes para as duas toxinas quando se compara à dose $\mathrm{CL}_{50}$. Portanto, a atividade biológica das toxinas do $B t$ sobre as larvas da LCM apresenta um maior impacto sobre o acúmulo de biomassa do que sobre a taxa de mortalidade. Assim, pode-se inferir que a taxa de inibição de crescimento é mais responsiva que a taxa de mortalidade à atividade da toxina. $\mathrm{O}$ maior impacto das toxinas do $B t$ sobre a taxa de inibição de crescimento do que sobre a taxa de mortalidade foi também observado para $O$. nubilalis, em que o $\mathrm{IC}_{50}$ (taxas de inibição de $50 \%$ do crescimento) variou de 0,33 a $1,33 \mathrm{\eta g} / \mathrm{cm}^{2}$, cerca de 6 vezes menor que a respectiva $\mathrm{CL}_{50}$ (Marçon et al., 1999). Embora a resposta dessa

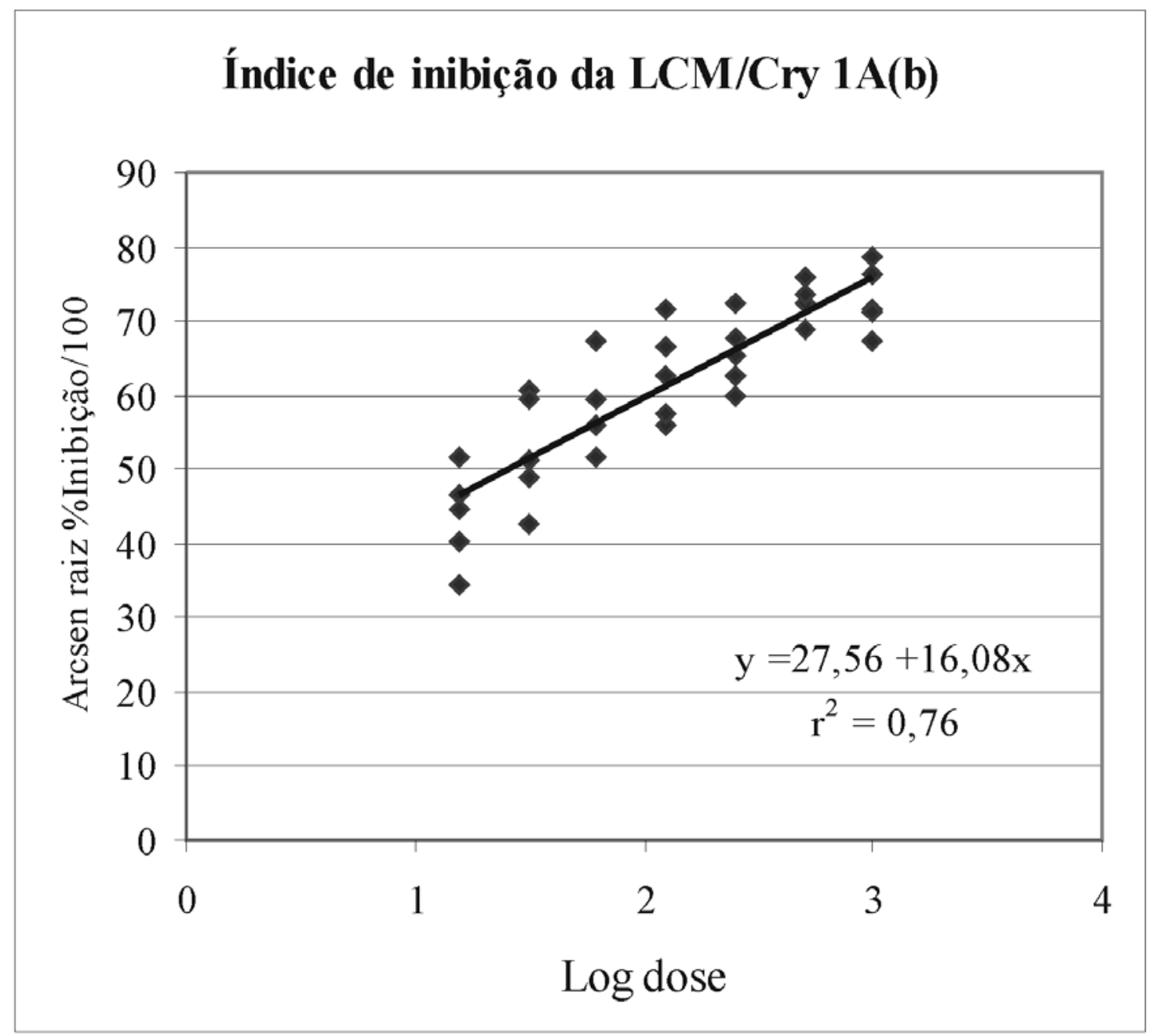

FIGURA 1. Curva de inibição de crescimento da lagarta-do-cartucho do milho sobrevivente em dieta artificial tratada na superfície com a toxina do Bt, Cry 1 A(b), Lincoln, NE, 2000. 
variável seja mais sensível que a taxa de mortalidade, devido à dificuldade de sua avaliação, devese preferir a outra nos monitoramentos rotineiros. Entretanto, para a avaliação da atividade subletal das toxinas, a taxa de inibição de crescimento, com base na biomassa, deve ser utilizada (Marçon et al., 1999). Uma alternativa para se considerar as duas variáveis nos testes de rotina, seria uma estimativa visual do tamanho das larvas e, neste caso, poder-se-ia usar as larvas desenvolvidas no tratamento controle para comparação (Sims et al., 1996). Foram observados casos em que larvas da LCM, mesmo 10 dias após a exposição, permaneceram no primeiro instar e, sem nenhum consumo aparente da dieta, sobreviveram durante os 10 dias sem se alimentar. É possível que exista algum mecanismo de defesa dessa espécie quando submetida a um estresse alimentar. Sabe-se, por exemplo, que a lagartaelasmo é um saprófita facultativo, isto é, na ausência de seus hospedeiros favoritos, alimentase de matéria orgânica em decomposição (Cheshire Jr. et al., 1977).

Recuperação do desenvolvimento larval - No bioensaio conduzido com a toxina Cry $1 \mathrm{~F}$, a taxa de sobrevivência da LCM foi muito baixa e o número de sobreviventes não foi suficiente para se estudar a recuperação de larvas após exposição

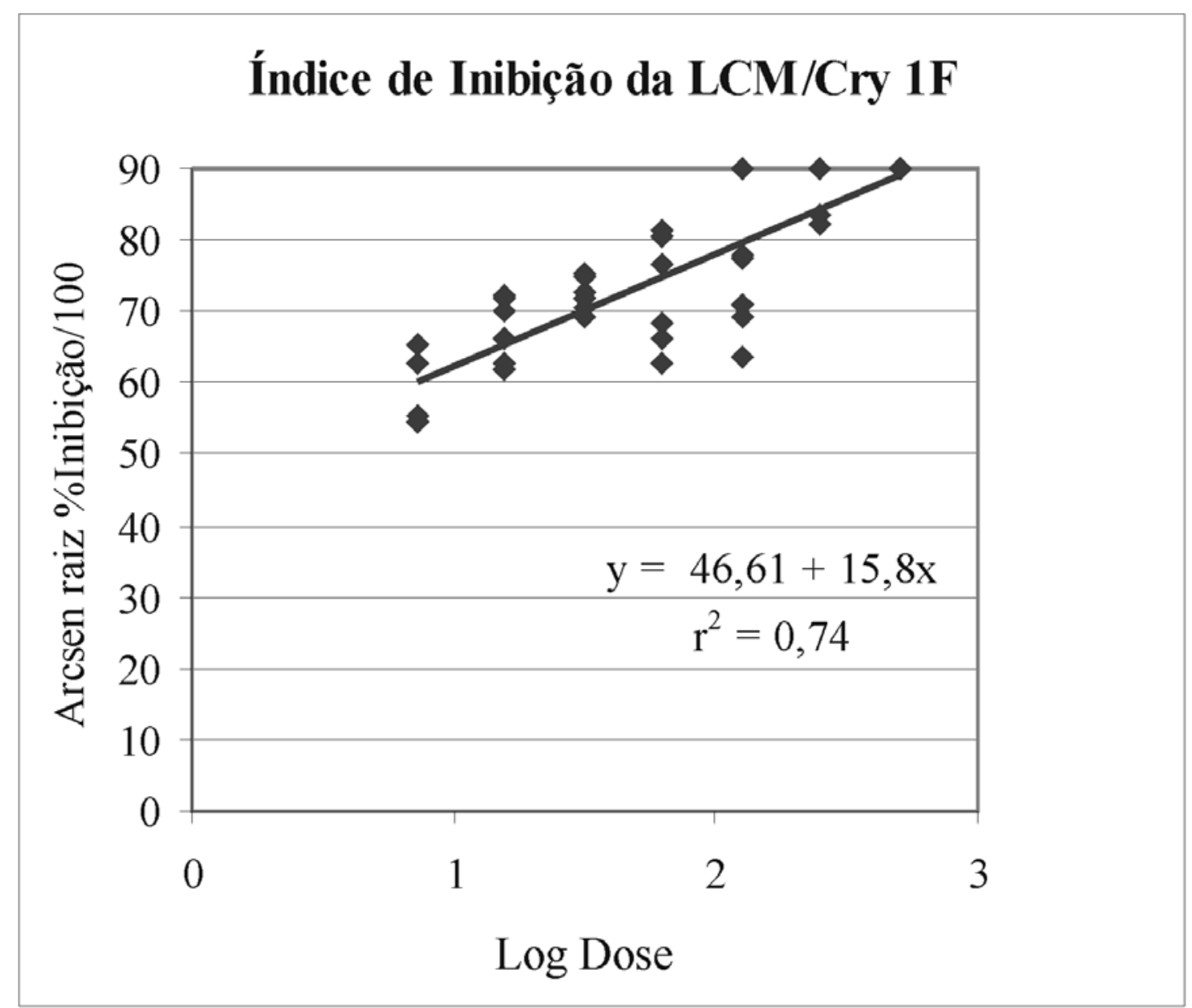

FIGURA 2. Curva de inibição de crescimento da lagarta-do-cartucho do milho sobrevivente em dieta artificial, tratada na superfície com a toxina do Bt, Cry 1F, Lincoln, NE, 2000. 
à toxina. Assim, este estudo foi realizado somente com larvas expostas à toxina Cry $1 \mathrm{~A}(\mathrm{~b})$. Das larvas da LCM transferidas da dieta tratada com a toxina do $B t$ para a dieta sem toxina, $62,8 \%$ sobreviveram e completaram o desenvolvimento larval passando à fase de pupa. $\mathrm{O}$ ganho de peso das larvas, após a mudança para a dieta sem toxina, aos 10 dias de idade, foi semelhante aos observados para as larvas testemunhas, sendo que, cinco dias após a transferência, a biomassa dessas larvas foi cerca de $300 \mathrm{mg}$ (Figura 3).

$\mathrm{Na}$ avaliação feita aos 15 dias de idade da LCM, ou seja, cinco dias após a alimentação com dieta sem toxina, as larvas provenientes do tratamento com a dose de $62,5 \eta \mathrm{g} / \mathrm{cm}^{2}$ apresentaram biomassa maior do que a das larvas do controle. Entretanto, a biomassa das pupas provenientes de todos os tratamentos foi semelhante, independente das doses da toxina. Portanto, esses dados indicam que, após a exposição das larvas à toxina do $B t$, uma alta taxa de sobreviventes pode completar seu ciclo, se alimento alternativo sem toxina for disponibilizado. Aparentemente, a biomassa acumulada até os 10 dias de exposição à toxina não afetou a biomassa das respectivas pupas, pois mesmo as larvas que permaneceram no primeiro instar durante os 10 dias de exposição à toxina, completaram seu ciclo quando foram transferidas para dieta sem toxina. Portanto, a atividade da proteína do $B t$ sobre a LCM vai além da toxicidade, apresentando também um importante componente de inibição alimentar (fago-deterrente). Segundo Van Frankenhuyzen (1993), a intoxicação está sempre associada com uma imediata inibição da alimentação. Por outro lado, a não-correlação $\left(\mathrm{R}^{2}=0.0024\right)$ entre a biomassa das larvas, ao final de 10 dias de exposição à toxina Cry $1 \mathrm{~A}(\mathrm{~b})$, e a biomassa das respectivas pupas (Figura 4) indica uma completa recuperação das larvas após a transferência para dieta sem toxina. Isso foi detectado já na avaliação da biomassa das larvas 5 dias após a alimentação

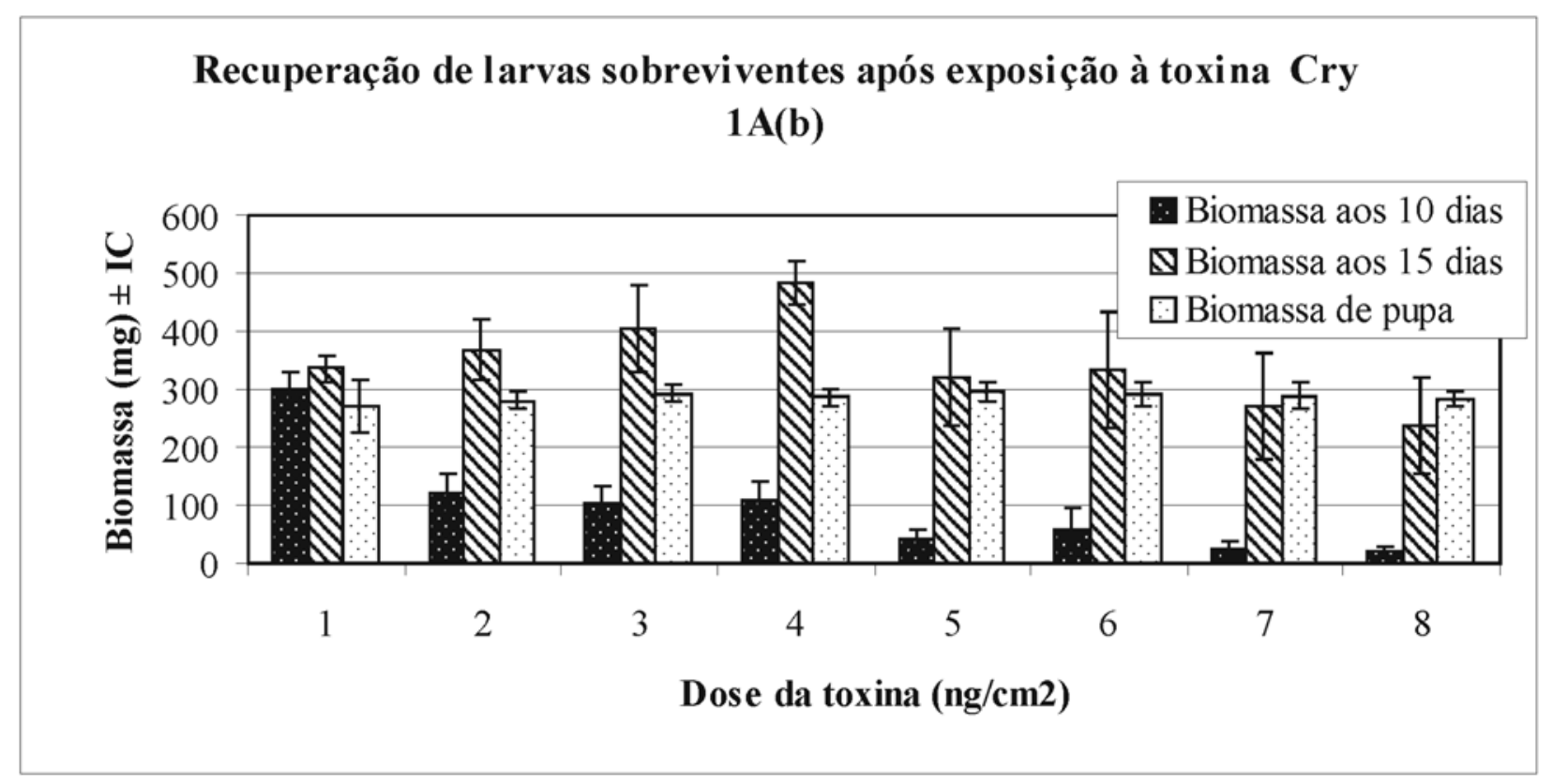

FIGURA 3. Biomassa da lagarta-do-cartucho do milho, sobrevivente à exposição por 10 dias à toxina do $B t$ Cry $1 \mathrm{~A}(\mathrm{~b})$ nas concentrações identificadas de 1 a 8 , sendo, respectivamente, de $0 ; 31,25 ; 62,5 ; 125 ; 250 ; 500$; 1000 e $2000 \eta \mathrm{g} / \mathrm{cm}^{2}$ de dieta e das respectivas pupas, Lincoln, NE, 2000. 


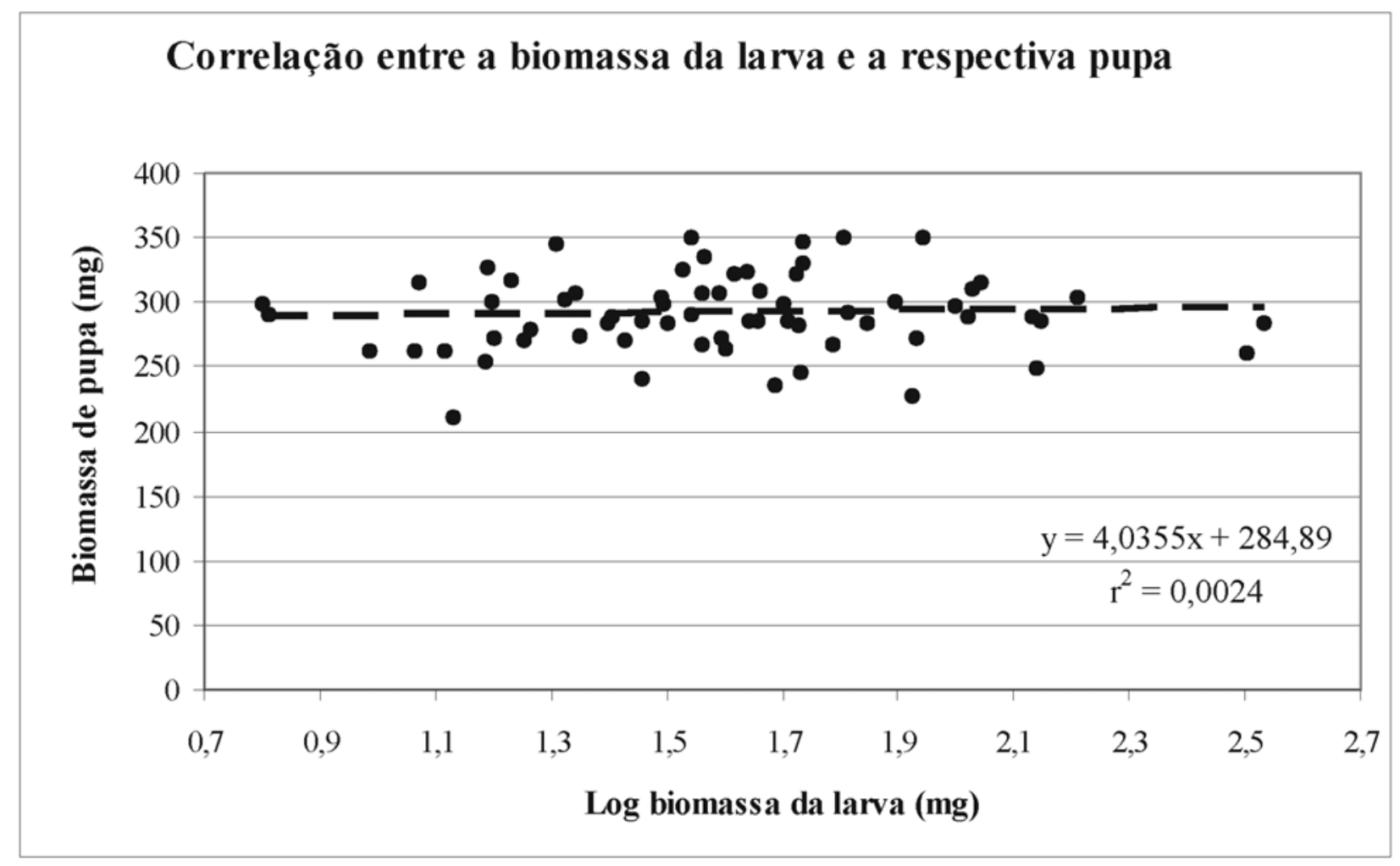

FIGURA 4. Correlação entre a biomassa da lagarta-do-cartucho do milho sobrevivente à exposição à toxina do Bt Cry $1 \mathrm{~A}(\mathrm{~b})$ por 10 dias e a biomassa das respectivas pupas, Lincoln, NE, 2000.

em dieta sem toxina, ou seja, aos 15 dias de idade (Figura 3). Esse fato sugere a inexistência de efeito residual da toxina na larva quando esta é removida para uma dieta sem a toxina. Esses fatos têm importantes implicações na definição das estratégias para o manejo da resistência.

\section{Agradecimentos}

Os autores manifestam seus agradecimentos às seguintes Instituições e pessoas: ao Departamento de Entomologia da UNL, à EMBRAPA, ao CNPq, à CAPES e à MONSANTO/DEKALB, nas pessoas do Dr. James Overman e Mrs. Nancy Adams. Registram também as contribuições dos Senhores Terry Spencer e Pit Clark durante a instalação, condução e documentação dos bioensaios. Esta publicação é a contribuição de número 14727 da série do jornal da Estação
Experimental Agrícola de Nebraska e uma contribuição de número 1197 do Departamento de Entomologia.

\section{Literatura citada}

BOHOROVA, N.; CABRERA, M.; ABARCA, C.; QUINTERO, R.; MACIEL, A. M.; BRITO, R. M.; HOISINGTON, D.; BRAVO, A. Susceptibility of four tropical Lepidopteran maize pests to Bacillus thuringiensis Cry I-type insecticidal toxins. Journal of Economic Entomology, College Park, v. 90, n. 2. p. 412415, 1997.

CARVALHO, R. P. L. Danos, flutuação populacional, controle e comportamento de Spodoptera frugiperda (Smith 1797) e susceptibilidade de diferentes genótipos de milho em 
condições de campo. 1970. 170 f. Tese (Doutorado), Escola Superior de Agricultura “ Luiz de Queiroz", Universidade de São Paulo, Piracicaba.

CHESHIRE Jr., J. M.; HENNINGSON, J.; ALL, J. N. Radiolabeling lesser cornstalk borer larvae for monitoring movements in soil habitats. Journal of Economic Entomology, College Park, v. 70, p. 578-580, 1977.

CORTEZ, M. G. R.; WAQUIL, J. M. Influência de cultivar e nível de infestação de Spodoptera frugiperda (J. E. Smith) (Lepidoptera: Noctuidae) no rendimento do sorgo. Anais da Sociedade Entomológica do Brasil, Londrina, v. 26, p. 407410, 1997.

CRUZ, I.; WAQUIL, J. M. Pragas da cultura do milho para silagem. In: CRUZ, J. C.; PEREIRA FILHO, I. A.; RODRIGUES, J. A. S.; FERREIRA, J. J. (Ed.). Produção e utilização de silagem de milho e sorgo. Sete Lagoas: Embrapa Milho e Sorgo, 2001. p.141-207.

CRUZ, I.; FIGUEIREDO, M. L. C.; OLIVEIRA, A. C.; VASCONCELOS, C. A. Damage of Spodoptera frugiperda (Smith) in different maize genotypes cultivated in soil under three levels of aluminum saturation. International Journal of Pest Management, London, v. 45, p. 293-296, 1999.

FEITELSON, J. S.; PAINE, J.; KIM, L. Bacillus thuringiensis: insects and beyond. Biotechnology, New York, v. 10, p. 271-275, 1992.

FERNANDES, O. D.; PARRA, J. R. P.; NETO, A. F.; PÍCOLI, R.; BORGATO, A. F.; DEMÉTRIO, C. G. B. Efeito do milho geneticamente modificado MON 810 sobre a lagarta-docartucho Spodoptera frugiperda (J. E. Smith,
1797) (Lepidoptera: Noctuidae). Revista Brasileira de Milho e Sorgo, Sete Lagoas, v. 2, n. 2, p. 25-35, 2003.

FONTES, E. M. G. Legal and regulatory concerns of transgenic plants in Brazil. Journal of Invertebrate Pathology, New York, v. 83, n. 2, p. $100-103,2003$.

GALLO, D.; NAKANO, O.; SILVEIRA NETO, S.; CARVALHO, R. P. L.; BATISTA, G. C.; BERTI FILHO, E.; PARRA, J. R. P.; ZUCCHI, R. A.; ALVES, S. B.; VENDRAMIM, J. D.; MARCHINI, L .C.; LOPES, J. R. S.; OMOTO, C. Entomologia Agrícola. São Paulo: Ceres, 2002. 920 p. (Biblioteca de Ciências Agrárias Luiz de Queiroz, v.10).

HERMSTADT, C.; SOARES, G. G.; WILCOX, E. R.; EDWARDS, D. L. New strain of Bacillus thuringiensis with activity against Coleopteran insects. Biotechnology, New York, v.4, p. 305308, 1986.

MACINTOSH, T. B.; STONE, S. R.; HUNST, P. L.; GREENPLATE, J. T.; MARRONE, P. G.; PERLAK, F. J.; FISCHHOFF, D. A.; FUCHS, R. L. Specificity and efficacy of purified Bacillus thuringiensis proteins against agronomically important insects. Journal of Invertebrate Pathology, New York, v. 56, p. 258-266, 1990.

MARÇON, P. C. R. G.; YONG, L. J.; STEFFELY, K. L.; SIEGFRIED, B. D. Baseline susceptibility of European corn borer (Lepidoptera: Crambidae) to Bacillus thuringiensis toxins. Journal of Economic Entomology, College Park, v. 92, n. 2, p. 279-285, 1999.

POLANCZYK, R. A.; SILVA, R. F. P. da.; FIUZA, L. M. Screening of Bacillus thuringiensis isolates pathogenic to Spodoptera frugiperda (J.E.Smith) (Lepidoptera: Noctuidae). Arquivo 
do Insituto. Biologico, São Paulo, v. 70, n. 1, p. 69-72, 2003.

SIMS, S. R.; GREEPLATE, J. T.; STONE,T. B.; CAPRIO, M. A.; GOULD, F. L. Monitoring strategies for early detection of Lepidoptera resistance to Bacillus thuringiensis insecticidal proteins. In: BROWN, T. M. (Ed.) Molecular genetics and evolution of pesticide resistance. Washington, DC: American Chemical Society, 1996. p. 229-242. (ACS Symposium Series, 645).

VAN FRANKENHUYZEN, K. Van. The challenge of Bacillus thuringiensis. In: ENTWISTLE, P. F.; CORY, J. S.; BAILEY, M. J.; HIGGS, S. (Ed.) Bacillus thuringiensis, an environmental biopesticide: theory and practice, Chichester: J. Wiley, 1993. p. 1-23.

VILELLA, F. M. F.; WAQUIL, J. M.; VILELA, E. F.; SIEGFRIED, B. D.; FOSTER, J. E. Selection of the fall armyworm, Spodoptera frugiperda (Smith) (Lepidoptera: Noctuidae) for survival on Cry 1A(b) Bt. toxin. Revista Brasileira de Milho e Sorgo, Sete Lagoas, v. 1, n. 3, p. 12-17, 2002.

VISSER, B.; MUNSTERMAN, E.; STROKES, A.; DIRLESE, W. G. A novel Bacillus thuringiensis gene encoding a Spodoptera exigua specific crystal protein. Journal of Bacteriology, Washington, v. 172, p. 6783-6788, 1990.

WAQUIL, J. M.; VIANA, P. A.; LORDELO, A. I.; CRUZ, I.; OLIVEIRA, A. C. Controle da lagarta-do-cartucho em milho com inseticidas químicos e biológicos. Pesquisa Agropecuária Brasileira, Brasília, v.17, n. 2, p. 163-166, 1982.

WAQUIL, J. M.;VILELLA, F. M. F.; FOSTER, J. E. Resistência do milho (Zea mays L.) transgênico (Bt.) à lagarta-do-cartucho, Spodoptera frugiperda (Smith) (Lepidóptera: Noctuidae). Revista Brasileira de Milho e Sorgo, Sete Lagoas, v. 1, n. 3, p. 1-11, 2002.

WILLIAMS, W. P.; DAVIS, F. M.;. BUCKLEY, P. M.; HEDIN, P. A.; BAKER, G. T.; LUTHE, D. S. Factors associated with resistance to fall armyworm (Lepidoptera: Noctuidae), and southwestern corn borer (Lepidoptera: Crambidae) in corn at different vegetative stage. Journal of Economic Entomology, College Park, v. 91, p. 1471-1480, 1998a.

WILLIAMS, W. P.; BUCKLEY, P. M.; SAGERS, J. B.; HANTEN, J. A. Evaluation of transgenic corn for resistance to corn earworm.(Lepidoptera: Noctuidae), fall armyworm (Lepidoptera: Noctuidae), and southwestern corn borer (Lepidoptera: Crambidae) in a laboratory bioassay. Journal of Agricultural Entomology, Clemson, v. 15, p. 105-112, 1998 b.

WILLIAMS, W. P.; DAVIS, F. M.; WINDHAM, G. L. Registration of Mp 708 germplasm line of maize. Crop Science, Madison, v. 30, p. 757, 1990. 